\title{
COMPARISON OF CARBON DIOXIDE AND HELIUM AS FIRE EXTINGUISHING AGENTS FOR SPACECRAFT
}

\author{
Youngjin Son and Paul D. Ronney \\ University of Southern California, USA \\ Suleyman Gokoglu \\ NASA Glenn Research Center, USA
}

\begin{abstract}
The effects of radiation heat transfer in microgravity compared to convection heat transfer in earth gravity for opposed-flow (downward) over thermally-thick fuel using low density foam fuel were investigated. Microgravity experiments on flame spread over thermally-thick fuels were conducted using foam fuels to obtain low density and thermal conductivity, and thus large flame spread rate compared to dense fuels such as PMMA. And thereby valid microgravity results were obtained even in 2.2 second drop-tower experiments not to mention for the longer duration tests in Zero Gravity Facility. Contrast to the conventional understanding, it was found that steady flame spread can occur over thick fuels in quiescent microgravity environments, especially when radiatively-active diluent gases such as $\mathrm{CO}_{2}$ were employed. This is proposed to result from radiative heat transfer from the flame to the fuel surface, which could lead to steady spread even when the amount of the heat transfer via conduction from the flame to the fuel bed is negligible. Radiative effects are more significant at microgravity conditions because the flame is thicker and thus the volume of radiating combustion products is larger as well.
\end{abstract}

These results suggested that helium may be a better inert or extinguishment agent on both a mass and a mole bases at microgravity even though $\mathrm{CO}_{2}$ is much better on a mole bases at earth gravity, and these are relevant to studies of fire safety in manned spacecraft, particularly the International Space Station that uses $\mathrm{CO}_{2}$ fire extinguishers. $\mathrm{CO}_{2}$ may not be as effective as an extinguishing agent at $\mu \mathrm{g}$ as it is at earth gravity in some conditions because of the differences in spread mechanisms between the two cases. In particular, the difference between conduction-dominated heat transport to the fuel bed at earth gravity and radiation-dominated heat transport at $\mu \mathrm{g}$ indicates that radiatively-inert diluent such as helium could be preferable in $\mu \mathrm{g}$ applications. Helium may be a superior fire suppression agent at $\mu \mathrm{g}$ on several bases. First, helium is more effective than $\mathrm{CO}_{2}$ on a mole basis (thus pressure times storage volume basis) at $\mu \mathrm{g}$, meaning that the size and weight of storage bottles would be smaller for the same fire-fighting capability. Second; helium is much more effective on a mass basis (by about 11 times) at $\mu \mathrm{g}$. Third; helium has no physiological activity, unlike $\mathrm{CO}_{2}$ that affects human respiration. Fourth, as compared to $\mathrm{N}_{2}$ or $\mathrm{CO}_{2}$, is not very soluble in water and thus has fewer tendencies to cause bloodstream bubble formation following rapid spacecraft cabin depressurization.

Paul D. Ronney

3650 McClintock Ave. OHE430

Los Angeles, CA, 90089

ronney@usc.edu

TEL: $213-740-0490$

FAX: 213-740-8071 


\title{
Comparison of carbon dioxide and helium as fire extinguishing agents for spacecraft
}

\author{
NASA grant NCC3-1056 \\ Youngjin Son, Paul D. Ronney \\ University of Southern California, \\ USA \\ Suleyman Gokoglu \\ NASA Glenn Research Center, USA
}

Department of Aerospace \& Mechanical Engineering 


\section{Motivation}

+ Flame spread over solid fuels; a useful means of understanding more complex two-phase non-premixed flames

+ Radiation is substantial, especially at reduced gravity - important in fire modeling in manned spacecraft

+ Benefits of this research

* Spacecraft fire safety - ISS will use $\mathrm{CO}_{2}$ fire extinguishers, but flames spread faster at reduced gravity with $\mathrm{CO}_{2}$ diluent due to radiative heating of fuel!

* He has lots of advantages over $\mathrm{CO}_{2}$ in ISS, at reduced gravity 


\section{Flame spread model for opposed flow with radiation}

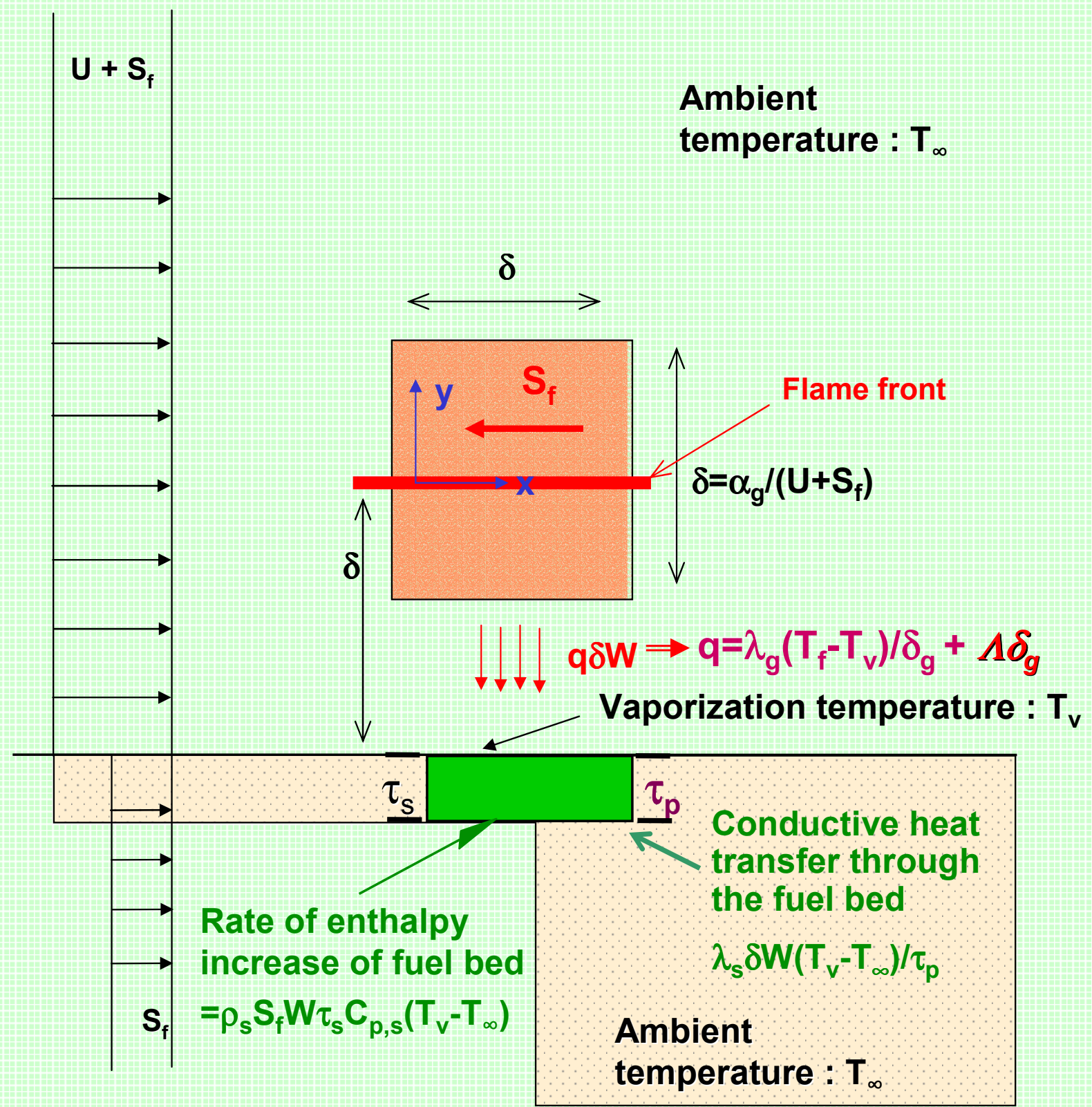

Department of Aerospace \& Mechanical Engineering 


\section{Theoretical background}

+ Equating heat generation from fuel with heat conduction through the gas q (= heat transferred to fuel bed per unit area)

+ de Ris (1969): Radiative transfer from external source to fuel bed leads to steady spread over thick fuel bed even if $\mathrm{U}=0$

+ Estimation of radiative flux from the flame to fuel bed leads to combined effects of conduction and radiation because hot gases such as $\mathrm{CO}_{2}$ and $\mathrm{SF}_{6}$ radiate by themselves:

$+q=\lambda_{g}\left(T_{f}-T_{v}\right) / \delta_{g}+\Lambda \delta_{g}, \Lambda=$ radiative emission per unit volume

* $\delta_{g}=\alpha_{g} / S_{f}$ assume $U=0$

+ Substitute into the equation

$$
S_{f} \sim \frac{q^{2} \delta_{g}}{\rho_{s} C_{p, s} \lambda_{s}\left(T_{v}-T_{\infty}\right)^{2}}
$$

$S_{f}=\left[\frac{\Lambda \alpha_{g}^{2}}{\sqrt{\alpha_{g} \rho_{s} C_{P, s} \lambda_{s}}\left(T_{v}-T_{\infty}\right)-\lambda_{g}\left(T_{f}-T_{v}\right)}\right]$ 


\section{Experimental setup}

$+\mu g$ experiments; 2.2 second drop tower facility \& Zero gravity facility were used

+ Fuel

* Problem with conventional thick fuels

$=$ Low $\mathrm{S}_{\mathrm{f}}$ (e.g. PMMA $\sim 0.006 \mathrm{~cm} / \mathrm{sec}$ in air,1 atm):

= Time scale $\sim \alpha / \mathrm{S}_{\mathrm{f}}^{2}$ too large for drop towers

w Length scale $\sim \alpha / \mathrm{S}_{\mathrm{f}}$ possibly too large even in space

- Need very low $\rho_{s} \lambda_{s} C_{p, s}$ - use foams

* Also high pressure $-\rho_{\mathrm{s}}$ higher, $\mathrm{Q} / \mathrm{V}$ higher

* Polyphenolic foam; used in floral arranging, density : $0.029 \mathrm{~g} / \mathrm{cm}^{3}$

+ Polyurethane foam; used in packing, density : 0.03 $\mathrm{g} / \mathrm{cm}^{3}$ 


\section{Diluent gas effect on $S_{f}$}

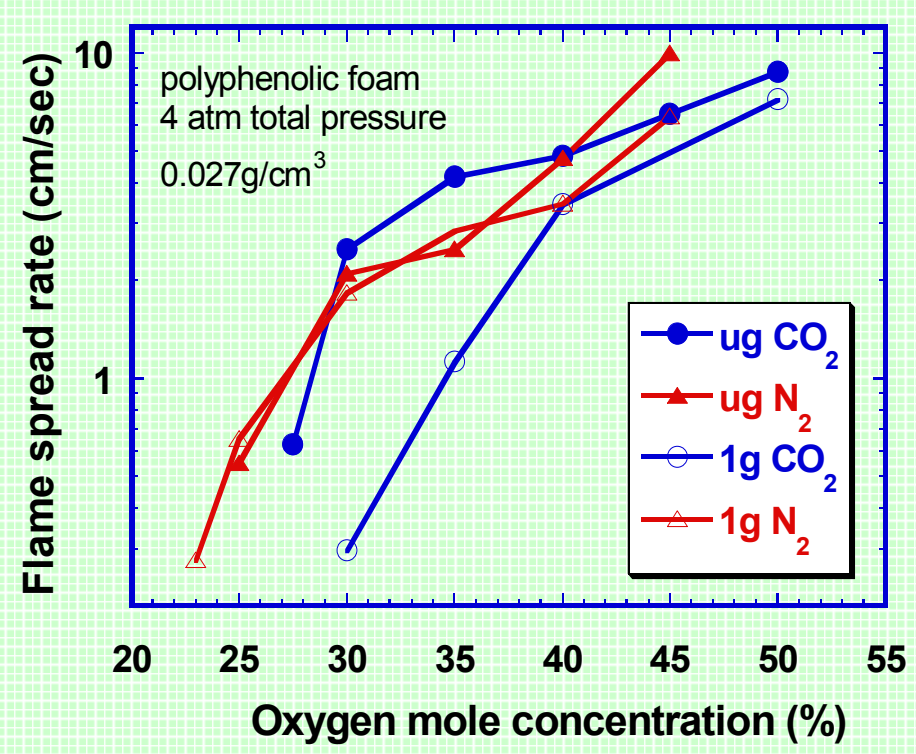

+ For $\mathrm{CO}_{2}, \mathrm{~S}_{\mathrm{f}}$ at $\mu \mathrm{g}$ is higher than at $1 \mathrm{~g}$, especially with $\mathrm{CO}_{2}$ diluent \& low $\mathrm{O}_{2}$ concentrations, whereas for $\mathbf{N}_{2}$ diluent, similar $S_{f}$

+ At $\mu g, S_{f}$ can be higher in $\mathrm{CO}_{2}$ than $\mathrm{N}_{2}$ at the same $\% \mathrm{O}_{2}$

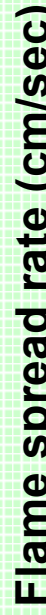

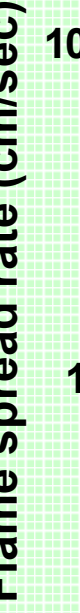

+ $\mathrm{He}$ and $\mathrm{CO}_{2}$ diluent shows similar $S_{f}$ for fixed $\mathrm{O}_{2}$ mole concentration even though mole based $\mathrm{C}_{\mathrm{p}}\left(\mathrm{CO}_{2}\right)>\mathrm{C}_{\mathrm{p}}(\mathrm{He})$, $\lambda_{g}\left(\mathrm{CO}_{2}\right)<\lambda_{g}(\mathrm{He})-\mathrm{T}_{\mathrm{f}}$ thus $S_{f}$ is higher in $\mathrm{He}$ than $\mathrm{CO}_{2}$ diluent; MOF (min. $\mathrm{O}_{2}$ fraction) at $1 \mathrm{~g}$ similar, but $\mathrm{He}$ has higher MOF at $\mu \mathrm{g}$ 


\section{Helium and $\mathrm{CO}_{2}$ comparison, $\mu \mathrm{g}$}

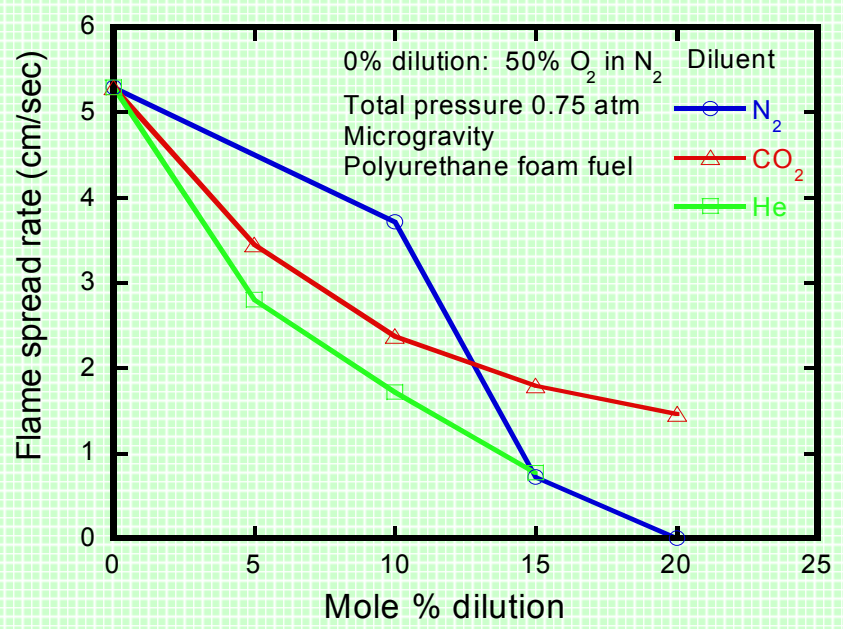

+ He shows slower $\mathrm{S}_{\mathrm{f}}$ than $\mathrm{CO}_{2}$ diluted case at $0.75 \mathrm{~atm}, 50 \% \mathrm{O}_{2}-\mathrm{N}_{2}$ of $0 \%$ dilution which is close to the space environment, $\mu \mathrm{g}$

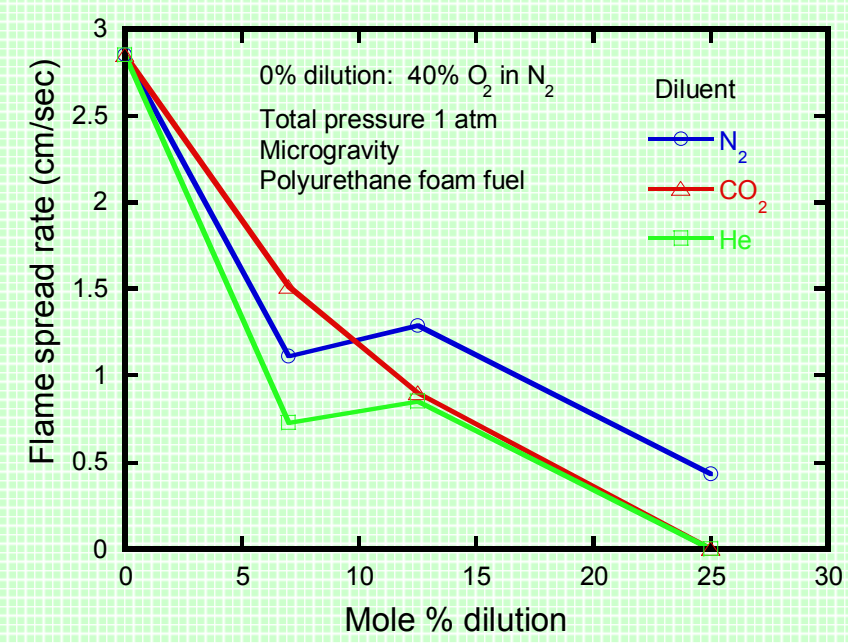

+ The trend between He and $\mathrm{CO}_{2}$ as an extinguisher or inert agent shows reverse as pressure increases; $\mathrm{CO}_{2}$ shows higher $\mathrm{S}_{\mathrm{f}}$ than $\mathrm{He}$ at $0.75 \mathrm{~atm}$ but lower $S_{f}$ at 2 atm

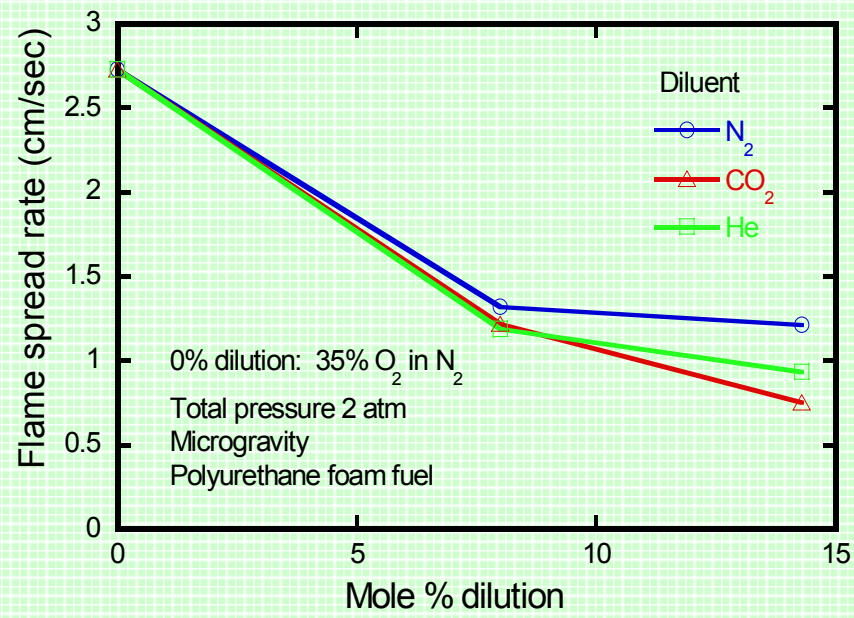

Department of Aerospace \& Mechanical Engineering 


\section{Helium and $\mathrm{CO}_{2}$ comparison, $1 \mathrm{~g}$}
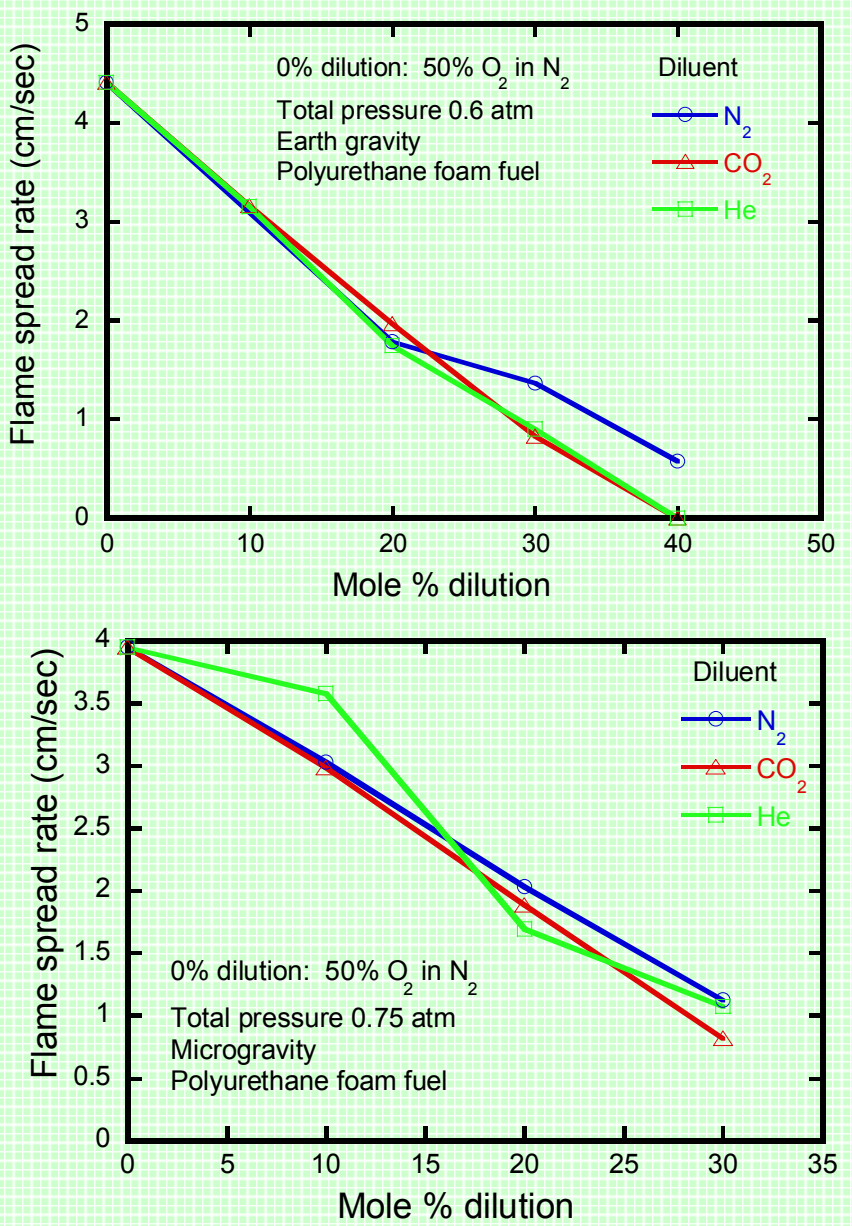

* He has more effects at $\mu \mathrm{g}$

+ 1) Lewis No. effect; high Le $\rightarrow$ lower $T_{f}$ $\rightarrow$ lower $\mathrm{S}_{\mathrm{f}}$ (Zhang, et.al., 1992)

+ 2) He; high $\lambda_{g} \rightarrow \alpha_{g}$ $\rightarrow$ thicker flame $\rightarrow$ more heat loss

+ 3) He; radiatively non-participating

+No re-

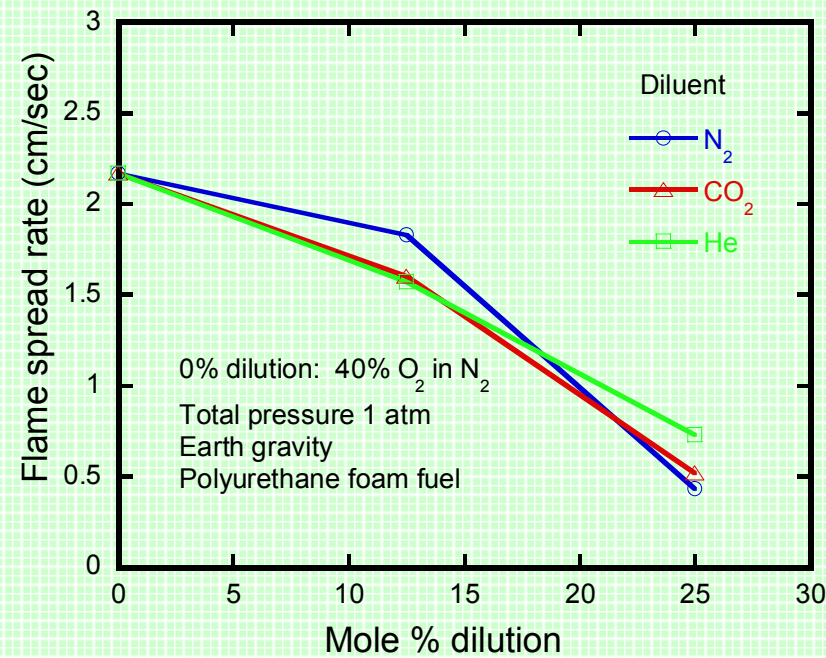
absorption +No re-radiation 


\section{Conclusion}

\section{+ Drop-tower experiments show}

+ $\mathrm{S}_{\mathrm{f}}$ at $\mu \mathrm{g}$ in $\mathrm{O}_{2}-\mathrm{CO}_{2}$ sometimes faster than $\mathrm{O}_{2}-\mathrm{N}_{2}$ or $\mathrm{O}_{2}-\mathrm{He}$ with same $\% \mathrm{O}_{2}$

* At high $\% \mathrm{O}_{2}$ \& low pressure, the addition of $\mathrm{CO}_{2}$ diluent results in faster $\mathrm{S}_{\mathrm{f}}$ than $\mathrm{He}$ at $\mu \mathrm{g}$, but not at $1 \mathrm{~g}$.

\section{Results due to}

+ Re-absorption and re-radiation of emitted radiation in $\mathrm{O}_{2}-\mathrm{CO}_{2}$ vs. no re-absorption and no re-radiation in $\mathrm{O}_{2}-\mathrm{N}_{2}$

- Thicker flames (more volume $\Rightarrow$ more radiation) at $\mu \mathrm{g}$

* Radiative preheating of the fuel bed by the gas is significant and re-absorption effects can prevent massive heat losses (thus extinction) in radiatively-active atmospheres at $\mu \mathrm{g}$

\section{* He mav be better extinguishing agent at $\mu \mathrm{g}$ than $\mathrm{CO}_{2}$}

* Same efficiency per mole (advantage for storage bottle mass \& volume)

* Much better per unit mass

+ No physiological impact $\left(\mathrm{CO}_{2}\right.$ affects human respiration)

* Helium is not soluble in water thus less tendency to cause bloodstream bubble formation following cabin depressurization

+ Relevant to fire safety in manned spacecraft, specially ISS which uses $\mathrm{CO}_{2}$ fire extinguisher 